\title{
A Novel Excitatory Paraventricular Nucleus to AgRP Neuron Circuit that Drives Hunger
}

\section{Citation}

Krashes, M. J., B. P. Shah, J. C. Madara, D. P. Olson, D. E. Strochlic, A. S. Garfield, L. Vong, et al. 2014. "A Novel Excitatory Paraventricular Nucleus to AgRP Neuron Circuit that Drives Hunger." Nature 507 (7491): 238-242. doi:10.1038/nature12956. http://dx.doi.org/10.1038/nature12956.

\section{Published Version}

doi:10.1038/nature12956

\section{Permanent link}

http://nrs.harvard.edu/urn-3:HUL.InstRepos:12987228

\section{Terms of Use}

This article was downloaded from Harvard University's DASH repository, and is made available under the terms and conditions applicable to Other Posted Material, as set forth at http:// nrs.harvard.edu/urn-3:HUL.InstRepos:dash.current.terms-of-use\#LAA

\section{Share Your Story}

The Harvard community has made this article openly available.

Please share how this access benefits you. Submit a story.

\section{Accessibility}




\title{
A Novel Excitatory Paraventricular Nucleus to AgRP Neuron Circuit that Drives Hunger
}

\author{
Michael J. Krashes ${ }^{*}, 1,2,3$, Bhavik P. Shah ${ }^{*}, 1$, Joseph C. Madara ${ }^{1}$, David P. Olson ${ }^{1,4}$, David E. \\ Strochlic ${ }^{5,6}$, Alastair S. Garfield ${ }^{1,7}$, Linh Vong ${ }^{1,8}$, Hongjuan Pei ${ }^{4}$, Mitsuko Watabe-Uchida ${ }^{9}$, \\ Naoshige Uchida ${ }^{6,9}$, Stephen D. Liberles ${ }^{5,6}$, and Bradford B. Lowel ${ }^{1,6}$ \\ ${ }^{1}$ Division of Endocrinology, Diabetes and Metabolism, Department of Medicine, Beth Israel \\ Deaconess Medical Center, Harvard Medical School, Boston, Massachusetts 02215, USA \\ ${ }^{5}$ Department of Cell Biology, Harvard Medical School, Boston, MA 02115, USA \\ ${ }^{6}$ Program in Neuroscience, Harvard University \\ ${ }^{7}$ Center for Integrative Physiology, University of Edinburgh, Edinburgh, UK \\ ${ }^{9}$ Center for Brain Science, Department of Molecular and Cellular Biology, Harvard University, 16 \\ Divinity Avenue, Cambridge, Massachusetts 02138, USA
}

\section{Summary}

\begin{abstract}
Hunger is a hard-wired motivational state essential for survival. Agouti-related peptide (AgRP)expressing neurons in the arcuate nucleus (ARC) at the base of the hypothalamus are crucial to its control. They are activated by caloric deficiency and, when naturally or artificially stimulated, they potently induce intense hunger and subsequent food intake ${ }^{1-5}$. Consistent with their obligatory role in regulating appetite, genetic ablation or pharmacogenetic inhibition of AgRP neurons decreases feeding $3,6,7$. Excitatory input to AgRP neurons is key in caloric-deficiencyinduced activation, and is notable for its remarkable degree of caloric state-dependent synaptic plasticity ${ }^{8-10}$. Despite the important role of excitatory input, its source(s) has been unknown. Here, through the use of Cre-recombinase-enabled, cell-specific neuron mapping techniques, we have discovered strong excitatory drive that, unexpectedly, emanates from the hypothalamic paraventricular nucleus, specifically from subsets of neurons expressing Thyrotropin-releasing hormone (TRH) and Pituitary adenylate cyclase-activating polypeptide (PACAP). Pharmacogenetic stimulation of these afferent neurons in sated mice markedly activates AgRP neurons and induces intense feeding. Conversely, acute inhibition in mice with caloric deficiency-induced
\end{abstract}

\footnotetext{
Correspondence and requests for materials should be addressed to B.B.L. (blowell@bidmc.harvard.edu). Equally contributing authors

${ }^{2}$ Current address: Diabetes, Endocrinology and Obesity Branch, National Institute of Diabetes and Digestive and Kidney Diseases, National Institutes of Health, Bethesda, Maryland 20892, USA

${ }^{3}$ Current address: National Institute on Drug Abuse, National Institutes of Health, Baltimore, Maryland 21224, USA

${ }^{4}$ Current address: Division of Pediatric Endocrinology, Departments of Pediatrics, University of Michigan, Ann Arbor, Michigan 48105, USA

${ }^{8}$ Current address: Cardiovascular and Metabolic Diseases, Novartis Institutes for BioMedical Research, Inc.100 Technology Square, Cambridge, Massachusetts 02139, USA

Author Contributions

M.J.K, B.P.S. and B.B.L. designed the experiments and analysed data. M.J.K., B.P.S., J.C.M., D.S., A.S.G., L.V., and H.P. performed experiments. M.J.K. generated Pdyn-ires-Cre, Trh-ires-Cre and Pacap-ires-Cre mice, D.P.O. generated Oxy-ires-Cre, Avp-ires-Cre, Crh-ires-Cre and R26-loxSTOPlox-L10-GFP mice and L.V. generated Vglut2-ires-Cre mice. M.W-U. and N.U. generated, provided and advised on use of AAV-FLEX-TVA-mCherry, AAV-FLEX-RG and SAD $\Delta$ G-EGFP (EnvA) viruses. S.D.L. advised on in situ hybridization experiments. M.J.K and B.B.L. wrote the manuscript with comments from all of the authors.

The authors declare no competing financial interests.

Supplementary Information is linked to the online version of the paper at www.nature.com/nature.
} 
hunger decreases feeding. Discovery of these afferent neurons capable of triggering hunger advances understanding of how this intense motivational state is regulated.

To identify monosynaptic inputs to AgRP neurons, we used a modified rabies virus $\mathrm{SAD} \Delta \mathrm{G}$-EGFP $\left(\right.$ EnvA) ${ }^{11}$ in combination with Cre-dependent helper adeno-associated viruses (AAVs) expressing TVA (receptor for the avian sarcoma leucosis virus glycoprotein EnvA; AAV8-FLEX-TVA-mCherry) and RG (rabies envelope glycoprotein;AAV8-FLEXRG). When used with Agrp-ires-Cre mice, TVA and RG, respectively, allow for rabies infection of AgRP neurons and subsequent retrograde transynaptic spread ${ }^{11,12}$ (Fig. 1a). Importantly, AAV targeting of the helper viruses was specific to AgRP neurons (Supplementary Fig. 1). Three weeks post-AAV transduction, we injected SAD $\Delta$ G-EGFP (EnvA) into the same area and examined brains 7 days later for $\mathrm{EGFP}^{+}$signal. We detected the largest number of EGFP ${ }^{+}$cells in the ARC (38\%), likely representing the initially infected AgRP neurons, and possibly local afferents (Fig. 1b; Supplementary Fig. 2). We next evaluated distant upstream anatomical areas for $\mathrm{EGFP}^{+}$neurons and found that the overwhelming majority were located in two hypothalamic nuclei, the dorsal medial hypothalamus (DMH; 26\%) which contains both glutamatergic and GABAergic neurons ${ }^{13}$ and the paraventricular hypothalamus $(\mathrm{PVH} ; 18 \%)$ consisting primarily of glutamatergic neurons $^{13}$ (Fig. 1b; Supplementary Fig. 2). Finally, we also observed a smaller number of $\mathrm{EGFP}^{+}$cells in other hypothalamic sites (Supplementary Fig. 2).

We next employed channelrhodopsin(ChR2)-assisted circuit mapping (CRACM) ${ }^{14,15}$ to both confirm and determine valence of functional monosynaptic connectivity between afferents and AgRP neurons. CRACM involves in vivo targeted expression of ChR2, a photoexcitable cation channel, in presumptive presynaptic upstream neurons (and their terminals), followed by ex vivo electrophysiologic assessment in acute brain slices of lightevoked postsynaptic currents in candidate downstream neurons. To investigate excitatory input to AgRP neurons, we stereotaxically injected Cre-dependent AAV expressing ChR2mCherry (AAV8-DIO-ChR2-mCherry) (Supplementary Fig. 3a) into brain sites of Vglut2ires-Cre; Npy-hrGFP mice ${ }^{13}$. Of note, VGLUT2 (official gene symbol, Slc17a6) is the glutamate synaptic vesicle transporter expressed in the hypothalamus, hence Vglut2-ires-Cre mice target relevant excitatory neurons ${ }^{13}$. As AgRP neurons co-express NPY, $N p y-h r G F P$ mice allow for visualization of AgRP neurons ${ }^{16,17}$. Consistent with the rabies tracing, we detected light-evoked excitatory post-synaptic currents (EPSCs) in all

VGLUT2 $2^{\mathrm{DMH}} \rightarrow \mathrm{AgRP}^{\mathrm{ARC}}$ neurons tested (latency between onset of light and $\mathrm{EPSC}=4.7 \pm$ $0.2 \mathrm{~ms}$; Fig. 1c; Supplementary Fig. 3f). These were blocked by CNQX, an AMPA receptor antagonist, confirming their glutamatergic nature. Next, we examined monosynaptic connections between VGLUT2 $2^{\mathrm{PVH}} \rightarrow \mathrm{AgRP}{ }^{\mathrm{ARC}}$ neurons and again, consistent with the rabies mapping, we observed light-evoked EPSCs in all AgRP neurons tested (latency $=4.9 \pm$ 0.4 ms; (Fig. 1d; Supplementary Fig. 3g). These also were blocked by CNQX.

In addition, we selectively expressed ChR2 in the ventral medial hypothalamus (VMH) and lateral hypothalamus (LH), two sites with few $\mathrm{EGFP}^{+}$cells, and also the ARC, which could provide local afferents, and investigated possible connectivity to AgRP neurons. In agreement with the negative rabies data, no light-evoked EPSCs were detected in 36 of 37 VGLUT2 $2^{\mathrm{VMH}} \rightarrow$ AgRPARC neurons tested (Supplementary Fig. 3b,h) or in any VGLUT2 $2^{\mathrm{LH}} \rightarrow \mathrm{AgRP}^{\mathrm{ARC}}$ neurons tested (Supplementary Fig. 3c,i). Likewise, we failed to detect light-evoked EPSCs in any VGLUT2 ${ }^{\mathrm{ARC}} \rightarrow$ AgRPARC neurons tested (Supplementary Fig. 3d,j). On the other hand, and as previously noted ${ }^{18}$, glutamatergic VMH neurons were monosynaptically connected to nearby Pro-opiomelanocortin (POMC) neurons $\left(\right.$ VGLUT2 ${ }^{\mathrm{VMH}} \rightarrow \mathrm{POMC}^{\mathrm{ARC}}$ ), as we observed light-evoked EPSCs in all POMC neurons tested (latency $=4.4 \pm 0.2 \mathrm{~ms}$; Supplementary Fig. 3e). 
The CRACM studies suggest marked differences in the strength of $\mathrm{VGLUT2}^{\mathrm{PVH}} \rightarrow \mathrm{AgRP}^{\mathrm{ARC}}$ versus VGLUT2 $2^{\mathrm{DMH}} \rightarrow \mathrm{AgRP}^{\mathrm{ARC}}$ inputs. First, the amplitude of light-evoked EPSCs generated from VGLUT2 ${ }^{\mathrm{PVH}}$ inputs were $\sim 3$-fold greater (Fig. 1e). Second, the effectiveness of light pulses in evoking EPSCs differed, with DMH inputs showing a much higher failure rate ( 32\% ;Fig. 1f; Supplementary Figure 4) compared with PVH inputs where time-locked EPSCs followed every light pulse ( $0 \%$ failure rate; Fig. 1g; Supplementary Figure 4). To test for consequences of these synaptic strength differences, we assessed the ability of VGLUT2 ${ }^{\mathrm{DMH}} \rightarrow \mathrm{AgRP}{ }^{\mathrm{ARC}}$ or VGLUT2 ${ }^{\mathrm{PVH}} \rightarrow \mathrm{AgRP}^{\mathrm{ARC}}$ inputs to fire action potentials in AgRP neurons. Whereas we never detected VGLUT2 $2^{\mathrm{DMH}} \rightarrow \mathrm{AgRP}^{\mathrm{ARC}}$ light-evoked action potentials (Fig. 1h), we observed VGLUT2 ${ }^{\mathrm{PVH}} \rightarrow \mathrm{AgRP}^{\mathrm{ARC}}$ light-evoked action potentials approximately $75 \%$ of the time (Fig. 1i), demonstrating potent, excitatory input to AgRP neurons originating from the PVH.

To determine which PVH neurons monosynaptically drive AgRP neurons, we employed numerous lines of Cre-expressing mice, each targeting subsets of PVH neurons, and then used CRACM to determine connectivity. Sim 1 encodes for the single minded 1 transcription factor required for developmental specification of the $\mathrm{PVH}$, and is thus expressed in the majority of PVH neurons, ${ }^{19}$ as verified in the Siml-Cre transgenic mouse ${ }^{20}$. Not surprisingly, we observed light-evoked EPSCs in all SIM1 ${ }^{\mathrm{PVH}} \rightarrow \mathrm{AgRP}^{\mathrm{ARC}}$ neurons tested (latency $=4.6 \pm 0.4 \mathrm{~ms}$; Fig. 2a). We next surveyed the Allen Brain Atlas for mRNAs highly enriched in the $\mathrm{PVH}$, and then assembled a series of ires-Cre knock-in mice targeting cells marked by Prodynorphin (Pdyn-ires-Cre; Supplementary Fig. 5), Oxytocin (Oxt-ires$\mathrm{Cre})^{21}$, Arginine Vasopressin (Avp-ires-Cre; Supplementary Fig. 6), CorticotropinReleasing Hormone (Crh-ires-Cre; Supplementary Fig. 7), TRH (Trh-ires-Cre; Supplementary Fig. 8) and PACAP (Pacap-ires-Cre; Supplementary Fig. 9). Following ChR2 delivery into the PVH, we failed to detect light-evoked EPSCs in all $\mathrm{PDYN}^{\mathrm{PVH}} \rightarrow \mathrm{AgRP}^{\mathrm{ARC}}$ (Fig. 2b), $\mathrm{OXY}^{\mathrm{PVH}} \rightarrow \mathrm{AgRP}^{\mathrm{ARC}}$ (Supplementary 10a), $\mathrm{AVP}^{\mathrm{PVH}} \rightarrow \mathrm{AgRP}^{\mathrm{ARC}}$ (Supplementary 10b), or $\mathrm{CRH}^{\mathrm{PVH}} \rightarrow \mathrm{AgRP}^{\mathrm{ARC}}$ (Supplementary 10c) neurons tested. On the other hand, we detected light-evoked EPSCs in all $\mathrm{TRH}^{\mathrm{PVH}} \rightarrow \mathrm{AgRP}^{\mathrm{ARC}}$ neurons (latency $=4.7 \pm 0.4 \mathrm{~ms}$; Fig. 2c) and all PACAP ${ }^{\mathrm{PVH}} \rightarrow \mathrm{AgRP}^{\mathrm{ARC}}$ neurons tested (latency $=4.8 \pm 0.3 \mathrm{~ms}$; Fig. $2 \mathrm{~d}$ ). These findings demonstrate that $\mathrm{TRH}^{\mathrm{PVH}}$ and $\mathrm{PACAP} \mathrm{PVH}^{\mathrm{PH}}$ neurons provide excitatory drive to AgRP neurons. It is not known if these excitatory inputs come from two distinct classes of $\mathrm{PVH}$ neurons or from one which co-expresses TRH and PACAP. The latter is possible given that $37 \%$ of TRH mRNA-expressing neurons are marked by Pacap-ires-Cre (Supplementary Fig. 11).

Innervation by $\mathrm{PACAP} \mathrm{PVH}^{\mathrm{PV}}$ neurons suggests that $\mathrm{PACAP}$, in addition to glutamate, could also activate AgRP neurons. To assess this, we exogenously added PACAP ${ }_{1-38}(100 \mathrm{nM})^{22}$ and determined effects on activity of synaptically isolated AgRP neurons (in the presence of picrotoxin (PTX) and kynurenate). Of note, PACAP $_{1-38}$ markedly depolarized and increased firing rate, and this was prevented by co-addition of the PAC1-receptor blocker, PACAP $\mathrm{P}_{6-38}$ $(200 \mathrm{nM})$ (Fig. 2e-h). Thus, in addition to glutamate, PACAP working through PAC1 receptors also likely plays an important role in the PACAP ${ }^{\mathrm{PVH}} \rightarrow \mathrm{AgRP}^{\mathrm{ARC}}$ circuit.

POMC and AgRP neurons lie in close proximity within the ARC, but have opposing effects on feeding ${ }^{2,23}$. If fidelity of the identified $\mathrm{PVH} \rightarrow \mathrm{AgRP} A R C$ neuron hunger circuit is to be high, then it should not also engage satiety-promoting POMC neurons. We evaluated this and found that the vast majority of $\mathrm{TRH}^{\mathrm{PVH}} \rightarrow \mathrm{POMC}^{\mathrm{ARC}}$ neurons (21 of 22) and all PACAP ${ }^{\mathrm{PVH}} \rightarrow \mathrm{POMC}^{\mathrm{ARC}}$ neurons are not monosynaptically connected (Fig. 3a, b, respectively). However, consistent with our observation that VGLUT2 ${ }^{\mathrm{VMH}} \rightarrow \mathrm{POMC}^{\mathrm{ARC}}$ neurons are connected (Supplementary Fig. 3e), and as a positive control for studies investigating $\mathrm{PACAP} \rightarrow \mathrm{POMC}^{\mathrm{ARC}}$ connections, we readily detected 
$\mathrm{PACAPVMH} \rightarrow \mathrm{POMC}{ }^{\mathrm{ARC}}$ monosynaptic connections (latency=4.5 $\pm 0.2 \mathrm{~ms} ;$ Fig. $3 \mathrm{c}$ ). These studies clearly demonstrate that the identified $\mathrm{PVH} \rightarrow \mathrm{AgRP}^{\mathrm{ARC}}$ neuron circuit selectively drives hunger-promoting AgRP neurons, but not satiety-promoting POMC neurons.

Fidelity should also exist in the downstream connections of orexigenic AgRP neurons, which have reciprocal connections with the PVH. GABAergic AgRP neurons are monosynaptically connected with a subset of satiety-promoting neurons in the $\mathrm{PVH}$, and importantly, this inhibitory connection drives feeding 5 . In the present study, we confirm this inhibitory $\mathrm{AgRP}{ }^{\mathrm{ARC}} \rightarrow \mathrm{PVH}$ connection following ChR2 expression in AgRP neurons, as we detected light-evoked IPSCs (latency $=5.2 \pm 0.3 \mathrm{~ms}$ ) in a subset $(55 \%)$ of $\mathrm{AGRP}^{\mathrm{ARC}} \rightarrow \mathrm{SIM} 1^{\mathrm{PVH}}$ neurons (Fig. 3d), which were blocked by PTX. If fidelity of this hunger-promoting, GABAergic reciprocal AgRPARC $\rightarrow \mathrm{PVH}$ connection is to be high, then it should not also engage and consequently inhibit the $\mathrm{TRH}^{\mathrm{PVH}}$ and $\mathrm{PACAP} \mathrm{PVH}^{\mathrm{PV}}$ neurons. As expected, we detected no AgRPARC $\rightarrow$ TRH ${ }^{\mathrm{PVH}}$ connections (Fig. 3e) and only rare $\mathrm{AgRP}^{\mathrm{ARC}} \rightarrow \mathrm{PACAP}^{\mathrm{PVH}}$ connections ( 1 of 12 neurons tested) (Fig. 3f). In total, the above studies demonstrate marked fidelity in the reciprocal TRH/PACAP ${ }^{\mathrm{PVH}}$ glutamatergic $\rightarrow$ $\mathrm{AgRP}{ }^{\mathrm{ARC}}$ GABAergic $\rightarrow$ Satiety ${ }^{\mathrm{PVH}}$ neuron circuit that drives feeding (Fig $3 \mathrm{~g}$ ).

To confirm function of the TRH ${ }^{\mathrm{PVH}}$ and PACAP ${ }^{\mathrm{PVH}}$ neurons, we targeted DREADDs (Designer Receptors Exclusively Activated by Designer Drugs; AAV8-DIO-hM3DqmCherry $)^{3}$ to the PVH. Upon binding of Clozapine-N-Oxide (CNO), hM3Dq activates neurons via the $\mathrm{Gq}$ signaling cascade ${ }^{24}$. After verifying in brain slices that $\mathrm{CNO}$ depolarized and increased firing frequency of $\mathrm{TRH}^{\mathrm{PVH}}$ and $\mathrm{PACAP} \mathrm{PVH}^{\mathrm{PV}}$ neurons (Fig. $4 \mathrm{a}$ and $4 \mathrm{~d}$, respectively), we found that acutely stimulating upstream $\mathrm{TRH}^{\mathrm{PVH}}$ or $\mathrm{PACAP} \mathrm{PVH}^{\mathrm{P}}$ neurons markedly induced Fos activity in AgRP cells, ipsilateral to the DREADD-activated upstream PVH neurons (Fig. 4b and 4e, respectively).

We next assessed effects of bilateral h3MDq-DREADD-mediated $\mathrm{TRH}^{\mathrm{PVH}}$ or PACAP ${ }^{\mathrm{PVH}}$ neuron stimulation on feeding behavior during the light cycle, a time when food intake is usually low because of feeding during the preceding dark cycle (as observed following saline injections, Fig. 4c and 4f, respectively - black lines). Importantly, acute activation by $\mathrm{CNO}$ injection of either $\mathrm{TRH}^{\mathrm{PVH}}$ or PACAP ${ }^{\mathrm{PVH}}$ neurons caused robust feeding (Fig. $4 \mathrm{c}$ and $4 \mathrm{f}$, respectively - red lines). Of note, this effect was absent following an overnight fast which itself elevates excitatory drive and consequently AgRP activity ${ }^{1,8,9}$ (Supplementary Fig. 12). To directly demonstrate that this enhanced feeding was mediated via AgRP neurons, we activated $\mathrm{TRH}^{\mathrm{PVH}}$ neurons (AAV8-DIO-hM3Dq-mCherry) while simultaneously inhibiting AgRPARC neurons (AAV8-DIO-hM4Di-mCherry ${ }^{3}$; Fig. 4g). Importantly, this significantly attenuated feeding (Fig. 4h). Finally, to examine whether endogenous activity of the $\mathrm{TRH}^{\mathrm{PVH}} \rightarrow \mathrm{AgRP}^{\mathrm{ARC}}$ pathway is physiologically relevant for feeding, we bilaterally transduced $\mathrm{TRH}^{\mathrm{PVH}}$ neurons with inhibitory DREADDs, which led to rapid hyperpolarization and decreased firing rate upon $\mathrm{CNO}$ application (as assessed in slice studies, Fig. 4i), and found that this manipulation drastically reduced food intake during the dark cycle (Fig. 4j). These studies demonstrate both the sufficiency and necessity of this novel $\mathrm{PVH} \rightarrow \mathrm{AgRP}{ }^{\mathrm{ARC}}$ orexigenic circuit in regulating food intake.

Given the vast number of studies implicating an anorexigenic role for the $\mathrm{PVH}^{5,20,25-28}$, it is remarkable to now discover a subset of neurons that drive feeding, through a reciprocal circuit (Fig. 3g). Failure of prior studies to detect orexigenic activity in the PVH is likely due to the reciprocal nature of this hunger circuit (leaving and returning to the $\mathrm{PVH}$ ) and the inhibitory aspect of its return arm ( $\mathrm{AgRP}{ }^{\mathrm{ARC}} \rightarrow$ Satiety ${ }^{\mathrm{PVH}}$ neurons). 


\section{Methods}

\section{Animals}

All animal care and experimental procedures were approved by the Beth Israel Deaconess Medical Center Institutional Animal Care and Use Committee. Mice were housed at 22_C24_C with a $12 \mathrm{~h}$ light/12 h dark cycle with standard mouse chow (Teklad F6 Rodent Diet $8664 ; 4.05 \mathrm{kcal} / \mathrm{g}, 3.3 \mathrm{kcal} / \mathrm{g}$ metabolizable energy, $12.5 \% \mathrm{kcal}$ from fat; Harlan Teklad, Madison, WI) and water provided ad libitum. All diets were provided as pellets. Mice were euthanized by $\mathrm{CO} 2$ narcosis.

\section{Generation of Mice}

Pdyn-ires Cre, Avp-ires-Cre, Crh-ires-Cre, Trh-ires-Cre and Pacap-ires-Cre mice were generated using recombineering techniques as previously described ${ }^{13,21}$. Briefly, a selection cassette containing an internal ribosomal entry sequence linked to Cre-recombinase and an Frt-flanked kanamycin resistance gene was targeted just downstream of the stop codon of the Prodynorphin, Arginine vasopressin, Corticotropin releasing hormone, Thyrotropin releasing hormone or Adenylate cyclase activating peptide 1 gene, respectively, in a bacterial artificial chromosome, so that Cre recombinase expression was driven by the endogenous genes. A targeting plasmid containing the Cre-containing selection cassette and $4 \mathrm{~kb}$ genomic sequence upstream and downstream of the Prodynorphin, Arginine vasopressin, Corticotropin releasing hormone, Thyrotropin releasing hormone or Adenylate cyclase activating peptide 1 stop codon, respectively was isolated and used for embryonic stem cell targeting. Correctly targeted clones were identified by long range PCR and injected into blastocysts. Chimeric animals generated from blastocyst implantation were then bred for germline transmission of the altered Prodynorphin, Arginine vasopressin, Corticotropin releasing hormone, Thyrotropin releasing hormone or Adenylate cyclase activating peptide 1-allele, respectively. Flp-deleter mice were then used to remove the neomycin selection cassette.

Generation of an enhanced Cre-dependent GFP reporter mice (R26-loxSTOPlox-L10-GFP) were generated using recombineering techniques as previously described ${ }^{20}$. A transgene containing a lox-flanked transcriptional blocking cassette followed by eGFP fused to the L10-ribosomal subunit ${ }^{31}$ was placed under the control of a CMV-enhancer/chicken betaactin promoter and targeted to the Rosa 26 locus using standard techniques ${ }^{32}$. Correctly targeted blastocysts were identified by long range PCR and confirmed by southern blotting and injected into blastocysts.

\section{Characterization of mice}

Pdyn-ires Cre, Avp-ires-Cre, Crh-ires-Cre, and Pacap-ires-Cre mice were crossed to R26loxSTOPlox-L10-GFP mice, sacrificed and sectioned at $30 \mu \mathrm{m}$. Brain sections were washed in $0.1 \mathrm{M}$ phosphate-buffered saline with Tween 20, pH 7.4 (PBST, 2 changes) and then incubated in the primary antiserum (anti-GFP, Abcam (1:1000), rabbit anti-hrGFP. After several washes in PBS, sections were incubated in Alexa fluorophore secondary antibody (Molecular Probes, 1:200) for 2 hours at room temperature. After several washes in PBS, sections were mounted onto gelatin-coated slides and fluorescent images were captured with Olympus VS120 Slide Scanner microscope.

Trh-ires-Cre mice were stereotaxically injected with Cre-dependent AAV8-DIO-mCherry, ${ }^{8}$ due to transient, early embryonic expression and subsequent deletion of floxed alleles by this mouse line, sacrificed and sectioned at $30 \mu \mathrm{m}$. Native fluorescence was used and fluorescent images were captured with Olympus VS120 Slide Scanner microscope. All 
digital images were processed in the same way between experimental conditions to avoid artificial manipulation between different data sets.

In situ mRNA hybridization experiments were performed for Pdyn-ires-Cre, Trh-ires-Cre and Pacap-ires-Cre mice (details below). Antibody staining experiments were performed for Avp-ires-Cre and Crh-ires-Cre mice. Briefly, Avp-ires-Cre; R26-loxSTOPlox-L10-GFP mice were co-localized with anti-AVP, Sigma (1:500), rabbit anti-AVP and anti-GFP, Abcam (1:1000), chicken anti-GFP. 48 hrs ICV colchicine treatment (Sigma, $10 \mathrm{ug}$ ), Crhires-Cre; R26-loxSTOPlox-L10-GFP mice were co-localized with anti-CRF, Peninsula Laboratories (1:2500), rabbit anti-CRF and anti-GFP, Abcam (1:1000), chicken anti-GFP.

All images were subsequently compared to in situ mRNA expression profiles generated by (C2013 Allen Institute for Brain Science; Allen Mouse Brain Atlas [Internet].

\section{Breeding strategies}

Vglut2-ires-Cre, Sim1-Cre, Pdyn-ires-Cre, Oxy-ires-Cre Avp-ires-Cre, Crh-ires-Cre, Trhires-Cre and Pacap-ires-Cre mice were bred to Npy-hrGFP transgenic mice to generate heterozygous Vglut2-ires-Cre; Npy-hrGFP, Siml-Cre; Npy-hrGFP, Pdyn-ires-Cre; NpyhrGFP, Oxy-ires-Cre; Npy-hrGFP, Avp-ires-Cre; Npy-hrGFP, Crh-ires-Cre; Npy-hrGFP, Trh-ires-Cre; Npy-hrGFP and Pacap-ires-Cre; Npy-hrGFP mice, respectively as previously reported. ${ }^{8}$ Vglut2-ires-Cre and Pacap-ires-Cre mice were bred to Pomc-hrGFP transgenic mice to generate heterozygous Vglut2-ires-Cre; Pomc-hrGFP and Pacap-ires-Cre; Pomc$h r G F P$ mice, respectively as previously reported ${ }^{13}$.

Agrp-ires-Cre, Pdyn-ires-Cre, Avp-ires-Cre, Crh-ires-Cre and Pacap-ires-Cre mice were bred to R26-loxSTOPlox-L10-GFP mice to generate heterozygous Agrp-ires-Cre; R26loxSTOPlox-L10-GFP, Pdyn-ires-Cre; R26-loxSTOPlox-L10-GFP, Avp-ires-Cre; R26loxSTOPlox-L10-GFP, Crh-ires-Cre; R26-loxSTOPlox-L10-GFP and Pacap-ires-Cre; R26loxSTOPlox-L10-GFP mice, respectively. Agrp-ires-Cre; R26-loxSTOPlox-L10-GFP mice were then bred to Sim1-Cre and Pacap-ires-Cre to generate heterozygous Agrp-ires-Cre; Sim1-Cre R26-loxSTOPlox-L10-GFP and Agrp-ires-Cre; Pacap-ires-Cre; R26-loxSTOPloxL10-GFP mice, respectively. All mice are on a mixed background.

\section{Viral injections}

Stereotaxic injections were performed as previously described. ${ }^{3}$ Mice were anesthetized with xylazine $(5 \mathrm{mg} / \mathrm{kg})$ and ketamine $(75 \mathrm{mg} / \mathrm{kg})$ diluted in saline $(350 \mathrm{mg} / \mathrm{kg})$ and placed into a stereotaxic apparatus (KOPF Model 963). After exposing the skull via small incision, a small hole was drilled for injection. A pulled-glass pipette with $20-40 \mathrm{~mm}$ tip diameter was inserted into the brain and virus was injected by an air pressure system. A micromanipulator (Grass Technologies, Model S48 Stimulator) was used to control injection speed at $25 \mathrm{nl} / \mathrm{min}$ and the pipette was withdrawn $5 \mathrm{~min}$ after injection. For retrograde rabies tracing, AAV-FLEX-TVA-mCherry, serotype 8 (titer $1.1 \times 10^{12}$ genomes copies per $\mathrm{ml}$ ) and AAV-FLEX-RG, serotype 8 (titer $1.4 \times 10^{12}$ genomes copies per ml $)^{12}$ were injected unilaterally into the ARC ( $200 \mathrm{nl}$, coordinates, bregma: AP:- $1.50 \mathrm{~mm}, \mathrm{DV}:-5.80 \mathrm{~mm}, \mathrm{~L}$ : $-0.20 \mathrm{~mm}$ ) of 5-6 weeks old mice. 21 days later $\mathrm{SAD} \Delta \mathrm{G}-\mathrm{EGFP}(\mathrm{EnvA})$ rabies (titer $10^{7}$ ) was unilaterally injected into the ARC ( $400 \mathrm{nl}$, coordinates, bregma: AP:-1.50 mm, DV:-5.80 $\mathrm{mm}$, L: $-0.20 \mathrm{~mm}$ ). For electrophysiology experiments, AAV-DIO-ChR2(H134R)-mCherry, serotype 8 (titer $1.3 \times 10^{12}$ genomes copies per $\left.\mathrm{ml}\right)^{29}$ was injected unilaterally into the DMH (20 nl, coordinates, bregma: AP:-1.70 mm, DV:-5.00 mm, L: -0.25 mm), PVH ( $25 \mathrm{nl}$, coordinates, bregma: AP:-0.70 mm, DV:-4.75 mm, L: - $0.20 \mathrm{~mm})$, VMH (25 nl, coordinates, bregma: AP:-1.40 mm, DV:-5.60 mm, L: $-0.40 \mathrm{~mm}$ ) or ARC (20 nl, coordinates, bregma: AP:-1.50 mm, DV:-5.80 mm, L: $-0.20 \mathrm{~mm}$ ) of 5-6 weeks old mice. For feeding and Fos 
studies, AAV-DIO-hM3Dq-mCherry, serotype 8 (titer $1.2 \times 10^{12}$ genomes copies per $\left.\mathrm{ml}\right)^{3}$ or AAV-DIO-hM4Di-mCherry, serotype 8 (titer $1.7 \times 10^{12}$ genomes copies per $\left.\mathrm{ml}\right)^{3}$ was injected bilaterally or unilaterally, respectively into the PVH ( $25 \mathrm{nl}$, coordinates, bregma: AP:-0.70 mm, DV:-4.75 mm, L: - $0.20 \mathrm{~mm}$ ) of 5-6 weeks old mice. For validation of Trhires-Cre mice, AAV-DIO-mCherry, serotype 8 (titer $1.2 \times 10^{12}$ genomes copies per $\left.\mathrm{ml}\right)^{8}$ or AAV-DIO-GFP, serotype 8 (titer $1.4 \times 10^{12}$ genomes copies per $\mathrm{ml}$ ) was injected bilaterally into the PVH ( $25 \mathrm{nl}$, coordinates, bregma: AP:-0.70 mm, DV:-4.75 mm, L: $-0.20 \mathrm{~mm}$ ) of 5-6 weeks old mice. All viruses were packaged at the Gene Therapy Center at the University of North Carolina. For postoperative care, mice were injected intraperitoneally with meloxicam $(0.5 \mathrm{mg} / \mathrm{kg})$. All stereotaxic injection sites were verified under electrophysiological microscopy (for electrophysiology-related studies) or by immunohistochemistry (for anatomy and in vivo studies). All "misses" or "partial hits" were excluded from data analyses.

\section{SADAG-EGFP (EnvA) rabies cell counting}

One week after SAD $\Delta$ G-EGFP (EnvA) rabies injection, mice were perfused and brains were sectioned and mounted as described above. For each brain $(n=6), 10 \mathrm{X}$ images were taken throughout 1 entire brain series using a Zeiss AxioImager Z.1 microscope and $\mathrm{EGFP}^{+}$cells were quantified using these images. Each $\mathrm{EGFP}^{+}$cell was assigned to a specific anatomical structure of the hypothalamus using The Mouse Brain in Stereotaxic Coordinates (Franklin \&Paxinos). As the number of labeled cell varied over multiple animals depending on the transduction rate of the viruses, the counted cells in each anatomical structure were expressed as a percentage of the total number of cells counted throughout each mouse brain. The percentages for each anatomical structure in a given mouse were then averaged over the entire cohort of mice (Supplementary Fig. 2).

\section{Electrophysiology and circuit mapping}

For brain slice preparation, 6-10 weeks old mice were anesthetized with isoflurane before decapitation and removal of the entire brain. Brains were immediately submerged in icecold, carbogen-saturated (95\% O2, 5\% CO2) high sucrose solution (238 mM sucrose, 26 $\mathrm{mM} \mathrm{NaHCO} 3,2.5 \mathrm{mM} \mathrm{KCl}, 1.0 \mathrm{mM}$ NaH2PO4, $5.0 \mathrm{mM} \mathrm{MgCl} 2,10.0 \mathrm{mM} \mathrm{CaCl} 2,11 \mathrm{mM}$ glucose). Then, $300 \mu \mathrm{M}$ thick coronal sections were cut with a Leica VT1000S Vibratome and incubated in oxygenated aCSF (126 mM NaCl, $21.4 \mathrm{mM} \mathrm{NaHCO}, 2.5 \mathrm{mM} \mathrm{KCl}, 1.2$ $\mathrm{mM} \mathrm{NaH} 2 \mathrm{PO} 4,1.2 \mathrm{mM} \mathrm{MgCl} 2,2.4 \mathrm{mM} \mathrm{CaCl} 2,10 \mathrm{mM}$ glucose) at $34^{\circ} \mathrm{C}$ for 30 minutes. Then, slices were maintained and recorded at room temperature $\left(20-24^{\circ} \mathrm{C}\right)$. The intracellular solution for voltage clamp recording contained the following (in $\mathrm{mM}$ ): $140 \mathrm{CsCl}, 1 \mathrm{BAPTA}$, 10 HEPES, $5 \mathrm{MgCl} 2,5 \mathrm{Mg}$-ATP, $0.3 \mathrm{Na}$ GTP, and 10 lidocaine $\mathrm{N}$-ethyl bromide (QX-314), pH 7.35 and $290 \mathrm{mOsm}$. The intracellular solution for current clamp recordings contained the following (in $\mathrm{mM}$ ): $128 \mathrm{~K}$ gluconate, $10 \mathrm{KCl}, 10 \mathrm{HEPES}, 1 \mathrm{EGTA}, 1 \mathrm{MgCl} 2,0.3 \mathrm{CaCl}$, 5 Na2ATP, 0.3 NaGTP, adjusted to $\mathrm{pH} 7.3$ with $\mathrm{KOH}$.

Photostimulation-evoked EPSCs and IPSCs were recorded in the whole cell voltage clamp mode, with membrane potential clamped at $-60 \mathrm{mV}$. Photostimulation -evoked EPSCs was recorded in presence of picrotoxin $(100 \mu \mathrm{M})$ to block inhibitory postsynaptic currents. All recordings were made using multiclamp 700B amplifier, and data were filtered at $2 \mathrm{kHz}$ and digitized at $10 \mathrm{kHz}$. To photostimulate Channelrhodopsin2-positive fibers, a laser or LED light source (473 nm; Opto Engine LLC; Thorlabs) was used. The blue light was focused on to the back aperture of the microscope objective, producing a wide-field exposure around the recorded cell of $10-15 \mathrm{~mW} / \mathrm{mm}^{2}$. The light power at the specimen was measured using an optical power meter PM100D (ThorLabs). The light output is controlled by a programmable pulse stimulator, Master-8 (AMPI Co. ISRAEL) and the pClamp 10.2 software (AXON Instruments). Photostimulation-evoked EPSCs/IPSCs detection protocol 
constitutes four blue light laser pulses administered 1 second apart during the first 4 seconds of a 8 second sweep, repeating for a total of 30 sweeps. When recording photostimulationevoked action potentials in AgRP neurons, current was injected into cells to keep the base line membrane potential at $\sim-60 \mathrm{mV}$. Mice with total misses, partial expression or expression outside the intended area were excluded from analysis after examination of mCherry expression.



To assess the effect of PACAP $1-38(100 \mathrm{nM})^{22}$ and PACAP $6-38(200 \mathrm{nM})$ onto AgRP neurons, we performed whole cell current clamp recordings on to 5-8 weeks old Npy-hrGFP mice. Synaptic blockers ( $1 \mathrm{mM}$ kynurenate and $100 \mu \mathrm{M}$ picrotoxin) were added in aCSF to synaptically isolate AgRP neurons.

To assess the effect of CNO on to TRH and PACAP neurons, 5- to 7-week-old Pacap-iresCre and Trh-ires-Cre mice were injected with AAV8-DIO-hM3Dq-mCherry into the PVH 2-3 weeks prior to recording. CNO was applied to bath solution through perfusion as previously reported. ${ }^{3}$ After acquisition of stable whole-cell recordings for 2-5 min, aCSF solution containing $5 \mu \mathrm{M}$ CNO was perfused into the brain slice preparation.

\section{Fos analysis}

Animals (Trh-ires-Cre; Npy-hrGFP; $\mathrm{n}=3$ and Pacap-ires-Cre; Npy-hrGFP; $\mathrm{n}=3$ mice), were handled for 10 consecutive days before the assay to reduce stress response, and then injected with $\mathrm{CNO}\left(0.3 \mathrm{mg} \mathrm{kg}^{-1}\right.$; i.p. $)$ at $9 \mathrm{am} .150 \mathrm{~min}$ later, the animals were sacrificed with $7 \%$ chloral hydrate diluted in saline $(350 \mathrm{mg} / \mathrm{kg}$ ) for histological assay. The mice were perfused and brains were sectioned as described above. Assessment of Fos induction was performed using a previously developed method ${ }^{8}$ modified for fluorescent colocalization with hrGFP in AgRP neurons. Brain sections were processed for immunohistochemical detection of Fos and hrGFP and counting.

Brain sections were washed in $0.1 \mathrm{M}$ phosphate-buffered saline with Tween 20, $\mathrm{pH} 7.4$ (PBST, 2 changes) and then incubated in the primary antiserum (anti-GFP, Abcam (1:1000), rabbit anti-hrGFP and anti-Fos, Calbiochem (1:10000). After several washes in PBS, sections were incubated Alexa fluorophore secondary antibodies (Molecular Probes, 1:200) for 2 hours at room temperature. After several washes in PBS, sections were mounted onto gelatin-coated slides and fluorescent 10X images were taken initially using a Zeiss AxioImager Z.1 microscope. Colocalization and quantification was further determined using fluorescent 20X images taken using a Zeiss AxioImager Z.1 microscope. Data are expressed as the percentage of all AgRP neurons (i.e., all hrGFP-positive neurons) that were doublepositive for Fos and hrGFP.

\section{Food intake studies}

Food intake studies on chow were performed as previously described. ${ }^{3,8,29}$ All animals (10to 12 -week-old male mice) were singly housed for at least 2.5 weeks following surgery and handled for 10 consecutive days before the assay to reduce stress response. Feeding studies were performed in home cages with ad lib food access. CNO was administered at $0.3 \mathrm{mg}$ 
$\mathrm{kg}^{-1}$ of body weight. Saline was delivered at the same volume to maintain consistency in the studies. Previous publications suggest the duration of the drugs effect at the dosage used throughout the studies is approximately $8 \mathrm{hrs}^{24}$. Mice with "missed" injections, incomplete "hits" or expression outside the area of interest were excluded from analysis after post hoc examination of mCherry expression. In this way, all food intake measurements were randomized and blind to the experimenter.

Light cycle food intake-Animals (Trh-ires-Cre; $\mathrm{n}=8$, Pacap-ires-Cre; $\mathrm{n}=7$ mice; Fig. 4c,f, or Trh-ires-Cre; Agrp-ires-Cre; $\mathrm{n}=4$, Trh-ires-Cre; $\mathrm{n}=4$ mice; Fig. 4h) were injected with either saline or $\mathrm{CNO}\left(0.3 \mathrm{mg} \mathrm{kg}^{-1}\right.$; i.p.) at 9 am and food intake was monitored 1 and/or $2 \mathrm{hrs}$ after i.p. injection from $9 \mathrm{am}-11 \mathrm{am}$. A full trial consisted of assessing food intake from the study subjects after they received injections of saline on day 1 and CNO on day 2. Animals received a day "off" between trials before another trial was initiated. The food intake data from all days following saline/CNO ( $\mathrm{n}=24$ trials for Trh-ires-Cre; $\mathrm{n}=21$ trials for Pacap-ires-Cre; Fig. 4c,f; $\mathrm{n}=12$ for Trh-ires-Cre; Agrp-ires-Cre; $\mathrm{n}=12$ trials for Trh-ires$\mathrm{Cre}$; Fig. 4h) injections was then averaged and combined for analysis.

Dark cycle food intake-Animals (Trh-ires-Cre; $\mathrm{n}=4$ mice; Fig. $4 \mathrm{j}$ ) were injected with either saline or $\mathrm{CNO}\left(0.3 \mathrm{mg} \mathrm{kg}^{-1}\right.$; i.p. $)$ at $6 \mathrm{pm}$ and food intake was monitored 1,2 and 3 hrs after i.p. injection from $6 \mathrm{pm}-9 \mathrm{pm}$. A full trial consisted of assessing food intake from the study subjects after they received injections of saline on day 1 and CNO on day 2 . Animals received a day "off" between trials before another trial was initiated. The food intake data from all days following saline/CNO ( $\mathrm{n}=12$ trials for Trh-ires-Cre; Fig. 4j) injections was then averaged and combined for analysis.

Fast-Refeed food intake-Animals (Trh-ires-Cre; $\mathrm{n}=8$, Pacap-ires-Cre; $\mathrm{n}=7$ mice; Supplementary Fig. 12) were fasted overnight at $5 \mathrm{pm}$ and the following day were injected with either saline or $\mathrm{CNO}\left(0.3 \mathrm{mg} \mathrm{kg}^{-1}\right.$; i.p. $)$ at $8: 30$ am and food intake was monitored 1.5 , 2.5 and 4.5 hrs after i.p. injection from 9 am-1 pm. A full trial consisted of assessing food intake from the study subjects after they received injections of saline on week 1 and CNO on week 2. Animals received a week "off" between trials before another trial was initiated. The food intake data from all days following saline/CNO ( $\mathrm{n}=16$ trials for Trh-ires-Cre; $\mathrm{n}=14$ trials for Pacap-ires-Cre; Supplementary Fig. 12) injections was then averaged and combined for analysis.

\section{In situ hybridization}

Pacap-ires-Cre; R26-loxSTOPlox-L10-GFP and Pdyn-ires-Cre; R26-loxSTOPlox-L10-GFP mice were sacrificed and brains were frozen fresh. Trh-ires-Cre mice with bilateral AAVDIO-GFP injections into the PVH were perfused with 4\% PFA, post-fixed for 2 hours and equilibrated in $20 \%$ sucrose overnight. $14 \mathrm{uM}$ cryosections were analyzed by in situ hybridization as previously described ${ }^{30}$ with minor modifications. Slides were fixed (4\% PFA), washed (2x RNase-free PBS), coverslipped, and imaged for intrinsic Cre-mediated GFP fluorescence. Digoxigenin labeled anti-sense cRNA probes were generated by T3 (Roche) in vitro transcription reactions using the complete coding sequence of $P d y n$ (5':ATGGCGTGGTCCAGGCTGATGC 3':TCAAACATCTAAATCTTCAGAATAGG) and a 914 bp fragment of Pacap cDNA (5':CTGCGTGACGCTTACGCCCT $3^{\prime}$ :TTGCCCCTGCAACCAGTGGG). A previously described murine $\mathrm{cDNA}^{33}$ (gift of Masanobu Yamada) was used to generate a Trh probe with SP6 RNA polymerase (Roche). Following hybridization, slides were incubated with anti-digoxigenin antibody conjugated to alkaline phosphatase (Roche, 1:200, 1hr RT), washed, and incubated (3-6 hr) in NBT/BCIP chromogenic substrate according to manufacturer's specifications (Roche). Slides were coverslipped and brightfield images were captured. Images were pseudocolored and 
compared with intrinsic Cre-mediated GFP fluorescence for colocalization and quantification.

\section{Statistical Analysis}

Statistical analyses were performed using Origin Pro 8.6 and Prism 6.0 (GraphPad)

Software.

\section{Supplementary Material}

Refer to Web version on PubMed Central for supplementary material.

\section{Acknowledgments}

This research was funded by the following NIH grants to BBL: R01 DK096010, R01 DK089044, R01 DK071051, R01 DK075632, R37 DK053477, BNORC Transgenic Core P30 DK046200 and BADERC Transgenic Core P30 DK0547521; to MJK: F32 DK089710, to DPO: K08 DK071561, to LV: F32 DK078478, to NU: R01 MH095953, and an ADA Mentor-Based Fellowship to BPS and BBL. We thank Daniel Cusher and Yanfang Li for mouse genotyping and Jenna Carroll and Yikun Guo for perfusions and tissue removal. Bryan L. Roth and Sarah C. Rogan for generating the AAV-DIO-hM3Dq-mCherry plasmid, Karl Deisseroth for generating the AAV-DIO-ChR2mCherry plasmid, and Anthony N. Hollenberg for the TRH riboprobe.

\section{References}

1. Takahashi KA, Cone RD. Fasting induces a large, leptin-dependent increase in the intrinsic action potential frequency of orexigenic arcuate nucleus neuropeptide Y/Agouti-related protein neurons. Endocrinology. 2005; 146:1043-1047. [PubMed: 15591135]

2. Aponte Y, Atasoy D, Sternson SM. AGRP neurons are sufficient to orchestrate feeding behavior rapidly and without training. Nat Neurosci. 2011; 14:351-355. [PubMed: 21209617]

3. Krashes MJ, et al. Rapid, reversible activation of AgRP neurons drives feeding behavior in mice. J Clin Invest. 2011; 121:1424-1428. [PubMed: 21364278]

4. Krashes MJ, Shah BP, Koda S, Lowell BB. Rapid versus Delayed Stimulation of Feeding by the Endogenously Released AgRP Neuron Mediators GABA, NPY, and AgRP. Cell Metab. 2013; 18:588-595. [PubMed: 24093681]

5. Atasoy D, Betley JN, Su HH, Sternson SM. Deconstruction of a neural circuit for hunger. Nature. 2012; 488:172-177. [PubMed: 22801496]

6. Luquet S, Perez FA, Hnasko TS, Palmiter RD. NPY/AgRP neurons are essential for feeding in adult mice but can be ablated in neonates. Science. 2005; 310:683-685. [PubMed: 16254186]

7. Gropp E, et al. Agouti-related peptide-expressing neurons are mandatory for feeding. Nat Neurosci. 2005; 8:1289-1291. [PubMed: 16158063]

8. Liu T, et al. Fasting activation of AgRP neurons requires NMDA receptors and involves spinogenesis and increased excitatory tone. Neuron. 2012; 73:511-522. [PubMed: 22325203]

9. Yang Y, Atasoy D, Su HH, Sternson SM. Hunger states switch a flip-flop memory circuit via a synaptic AMPK-dependent positive feedback loop. Cell. 2011; 146

10. Pinto S, et al. Rapid rewiring of arcuate nucleus feeding circuits by leptin. Science. 2004; 304:110115. [PubMed: 15064421]

11. Wickersham IR, Finke S, Conzelmann KK, Callaway EM. Retrograde neuronal tracing with a deletion-mutant rabies virus. Nat Methods. 2007; 4:47-49. [PubMed: 17179932]

12. Watabe-Uchida M, Zhu L, Ogawa SK, Vamanrao A, Uchida N. Whole-brain mapping of direct inputs to midbrain dopamine neurons. Neuron. 2012; 74:858-873. [PubMed: 22681690]

13. Vong L, et al. Leptin action on GABAergic neurons prevents obesity and reduces inhibitory tone to POMC neurons. Neuron. 2011; 71:142-154. [PubMed: 21745644]

14. Petreanu L, Huber D, Sobczyk A, Svoboda K. Channelrhodopsin-2-assisted circuit mapping of long-range callosal projections. Nature neuroscience. 2007; 10:663-668. 
15. Atasoy D, Aponte Y, Su HH, Sternson SM. A FLEX switch targets Channelrhodopsin-2 to multiple cell types for imaging and long-range circuit mapping. J Neurosci. 2008; 28:7025-7030. [PubMed: 18614669]

16. Hahn TM, Breininger JF, Baskin DG, Schwartz MW. Coexpression of Agrp and NPY in fastingactivated hypothalamic neurons. Nat Neurosci. 1998; 1:271-272. [PubMed: 10195157]

17. van den Pol AN, et al. Neuromedin B and gastrin-releasing peptide excite arcuate nucleus neuropeptide $\mathrm{Y}$ neurons in a novel transgenic mouse expressing strong Renilla green fluorescent protein in NPY neurons. J Neurosci. 2009; 29:4622-4639. [PubMed: 19357287]

18. Sternson SM, Shepherd GM, Friedman JM. Topographic mapping of VMH --> arcuate nucleus microcircuits and their reorganization by fasting. Nature neuroscience. 2005; 8:1356-1363.

19. Michaud JL, Rosenquist T, May NR, Fan CM. Development of neuroendocrine lineages requires the bHLH-PAS transcription factor SIM1. Genes Dev. 1998; 12:3264-3275. [PubMed: 9784500]

20. Balthasar N, et al. Divergence of melanocortin pathways in the control of food intake and energy expenditure. Cell. 2005; 123:493-505. [PubMed: 16269339]

21. Wu Z, et al. An obligate role of oxytocin neurons in diet induced energy expenditure. PLoS One. 2012; 7:e45167. [PubMed: 23028821]

22. Fukushima Y, et al. Role of endogenous PACAP in catecholamine secretion from the rat adrenal gland. American journal of physiology Regulatory, integrative and comparative physiology. 2001; 281:R1562-1567.

23. Zhan $\mathrm{C}$, et al. Acute and long-term suppression of feeding behavior by POMC neurons in the brainstem and hypothalamus, respectively. J Neurosci. 2013; 33:3624-3632. [PubMed: 23426689]

24. Alexander GM, et al. Remote control of neuronal activity in transgenic mice expressing evolved G protein-coupled receptors. Neuron. 2009; 63:27-39. [PubMed: 19607790]

25. Leibowitz SF, Hammer NJ, Chang K. Hypothalamic paraventricular nucleus lesions produce overeating and obesity in the rat. Physiol Behav. 1981; 27:1031-1040. [PubMed: 7335803]

26. Gold RM, Jones AP, Sawchenko PE. Paraventricular area: critical focus of a longitudinal neurocircuitry mediating food intake. Physiol Behav. 1977; 18:1111-1119. [PubMed: 928534]

27. Stanley BG, Leibowitz SF. Neuropeptide Y injected in the paraventricular hypothalamus: a powerful stimulant of feeding behavior. Proc Natl Acad Sci U S A. 1985; 82:3940-3943. [PubMed: 3858854]

28. Cowley MA, et al. Integration of NPY, AGRP, and melanocortin signals in the hypothalamic paraventricular nucleus: evidence of a cellular basis for the adipostat. Neuron. 1999; 24:155-163. [PubMed: 10677034]

29. Kong D, et al. GABAergic RIP-Cre neurons in the arcuate nucleus selectively regulate energy expenditure. Cell. 2012; 151:645-657. [PubMed: 23101631]

30. Montmayeur JP, Liberles SD, Matsunami H, Buck LB. A candidate taste receptor gene near a sweet taste locus. Nat Neurosci. 2001; 4:492-498. [PubMed: 11319557]

31. Heiman M, et al. A translational profiling approach for the molecular characterization of CNS cell types. Cell. 2008; 135:738-748. [PubMed: 19013281]

32. Srinivas $S$, et al. Cre reporter strains produced by targeted insertion of EYFP and ECFP into the ROSA26 locus. BMC Dev Biol. 2001; 1:4. [PubMed: 11299042]

33. Satoh T, Yamada M, Monden T, Iizuka M, Mori M. Cloning of the mouse hypothalamic preprothyrotropin-releasing hormone (TRH) cDNA and tissue distribution of its mRNA. Brain Res Mol Brain Res. 1992; 14:131-135. [PubMed: 1323011] 

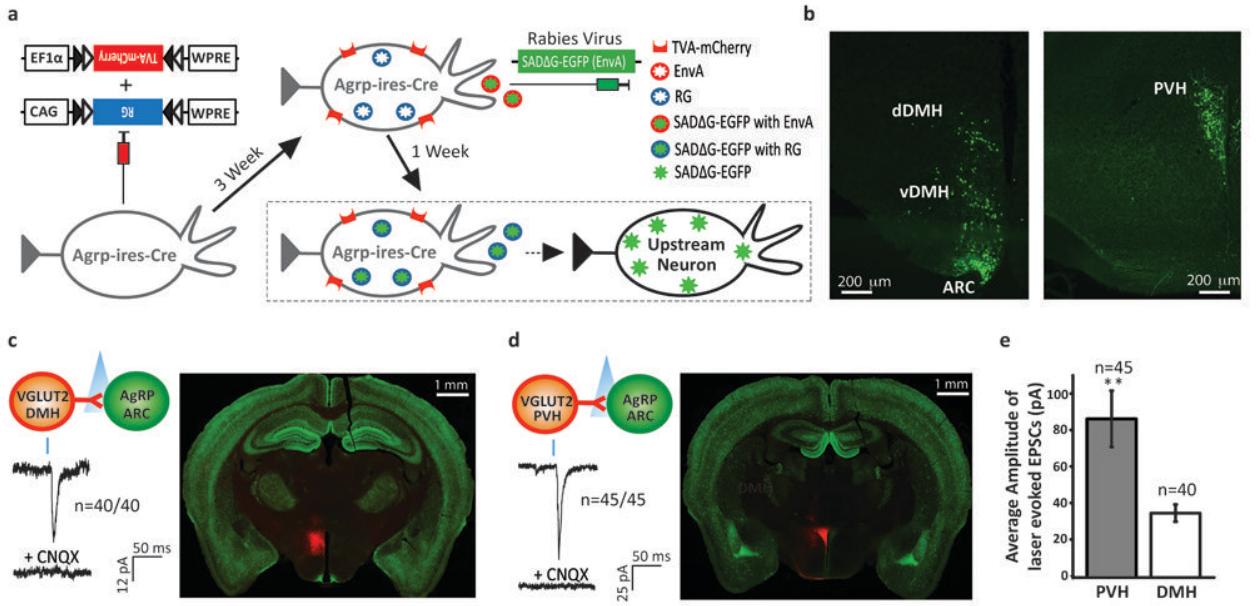

f

g

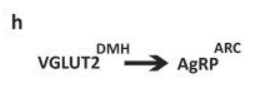
$\mathrm{VGWT}^{\mathrm{PVH}} \rightarrow \mathrm{ABC}^{\mathrm{ARC}}$

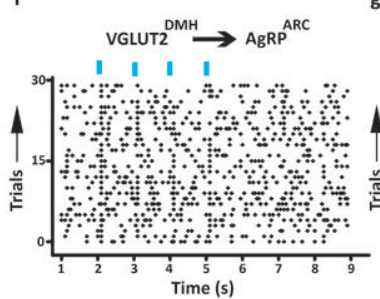
VGLUT2 ${ }^{\text {PVH }} \rightarrow$ AgRP $^{A R C}$ (1) 1 I
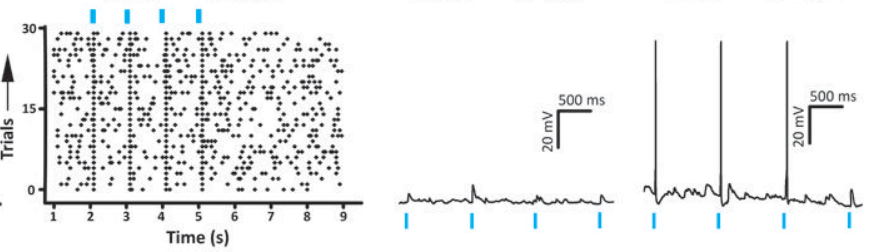

Figure 1. Mapping and evaluating connectivity of inputs to $\operatorname{AgRP}^{\mathrm{ARC}}$ neurons

a, Rabies schematic.

b, EGFP detected in the ARC and DMH (Left) and PVH (Right) in Agrp-ires-Cre mice. c,d, Top, schematic shows connections being tested. Right, representative brains from mice stereotaxically injected with AAV8-DIO-ChR2-mCherry (red $=$ ChR2-mCherry, green $=$ hrGFP from Npy-hrGFP. Bottom, representative traces showing assessment of light-evoked excitatory postsynaptic currents (EPSCs) with blue tic indicating the light pulse $(473 \mathrm{~nm}$ wavelength, 2 msec). Mice used were Vglut2-ires-Cre; Npy-hrGFP. ChR2 was targeted to (c) DMH and (d) PVH. CNQX = AMPA receptor blocker.

e, Average amplitude of light-evoked EPSCs (pA) in AgRP neurons ( $\mathrm{n}=40$ for VGLUT2 $2^{\mathrm{DMH}} \rightarrow \mathrm{AgRP}^{\mathrm{ARC}}$ group; $\mathrm{n}=45$ for VGLUT2 ${ }^{\mathrm{PVH}} \rightarrow \mathrm{AgRP}^{\mathrm{ARC}}$ group). Results are shown as mean $\pm \mathrm{SEM}, * *=p<0.001$; see Supplementary Information for statistical analyses. $\mathbf{f}, \mathbf{g}$, Representative raster plots of EPSCs for (f) VGLUT2 ${ }^{\mathrm{DMH}} \rightarrow \mathrm{AgRP}^{\mathrm{ARC}}$ and (g) $\mathrm{VGLUT}_{2}{ }^{\mathrm{PVH}} \rightarrow \mathrm{AgRP} \mathrm{ARC}$

$\mathbf{h , i}$, Representative traces showing light-evoked changes in membrane potentials in AgRP neurons for (h) VGLUT2 $2^{\mathrm{DMH}} \rightarrow \mathrm{AgRP}^{\mathrm{ARC}}$ and (i) VGLUT2 ${ }^{\mathrm{PVH}} \rightarrow \mathrm{AgRP} \mathrm{ARC}$. e. $\mathrm{n}=45$ for VGLUT2 $2^{\mathrm{PVH}} \rightarrow \mathrm{AgRP}^{\mathrm{ARC}}$ group; $\mathrm{n}=40$ for $\mathrm{VGLUT} 2^{\mathrm{DMH}} \rightarrow \mathrm{AgRP}^{\mathrm{ARC}}$ group. Data represent mean \pm SEM. P values for unpaired comparisons were calculated by twotailed Student's t-test. ${ }^{*} \mathrm{p}<0.05,{ }^{*} \mathrm{p}<<0.001$. 


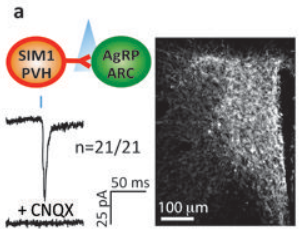

e


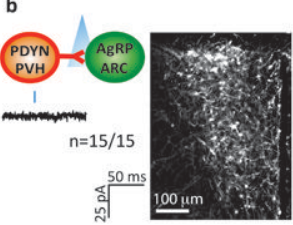

f
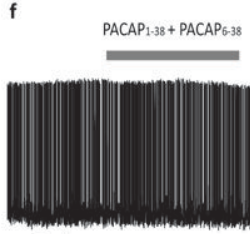

: in $^{2 \min }$

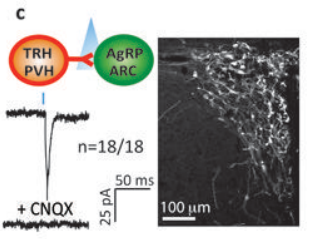

d

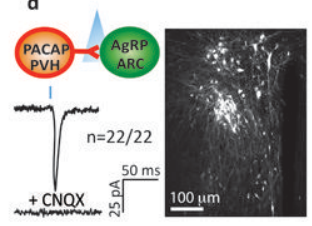

g
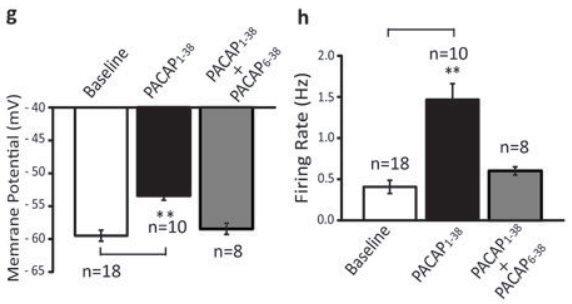

Figure 2. TRH ${ }^{\mathrm{PVH}}$ and PACAP ${ }^{\mathrm{PVH}}$ neurons provide excitatory input to AgRP neurons a-d, Top, schematic shows connections being tested. Right, representative brain sections of PVH injected with AAV8-DIO-ChR2-mCherry (white $=$ ChR2-mCherry). Bottom, representative traces showing assessment of light-evoked EPSCs with blue tic indicating the light pulse (473 nm wavelength, $2 \mathrm{msec}$ ). Mice used were (a) Sim1-Cre; Npy-hrGFP, (b) Pdyn-ires-Cre; Npy-hrGFP, (c) Trh-ires-Cre; Npy-hrGFP, and (d) Pacap-ires-Cre; NpyhrGFP. CNQX = AMPA receptor blocker.

e-h, Baseline and effects of PACAP $(100 \mathrm{nM})$ with or without PAC1R blocker $\left(\right.$ PACAP $_{6-38}$; $200 \mathrm{nM})$ on membrane potential and firing rate of AgRP neurons $(\mathrm{n}=18, \mathrm{n}=10, \mathrm{n}=8$, respectively). Results are shown as mean \pm SEM, $* *=p<0.001$; see Supplementary Information for statistical analyses.

g, h. $\mathrm{n}=18$ for baseline group; $\mathrm{n}=10$ for $\mathrm{PACAP}_{1-38}$ group; $\mathrm{n}=8$ for $\mathrm{PACAP}_{1-38}+$ $\mathrm{PACAP}_{6-38}$ group. $\mathrm{P}$ values for pair-wise comparisons (baseline versus $\mathrm{PACAP}_{1-38}$ group) and unpaired comparisons (baseline versus $\mathrm{PACAP}_{1-38}+\mathrm{PACAP}_{6-38}$ group) were calculated by two-tailed Student's t-test. $* \mathrm{p}<0.05, * * \mathrm{p}<0.001$. 
a

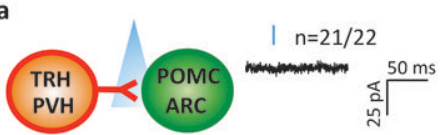

b
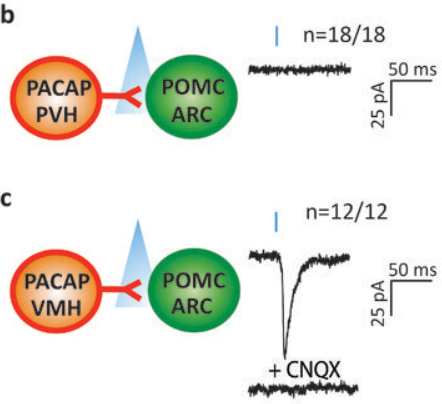

d
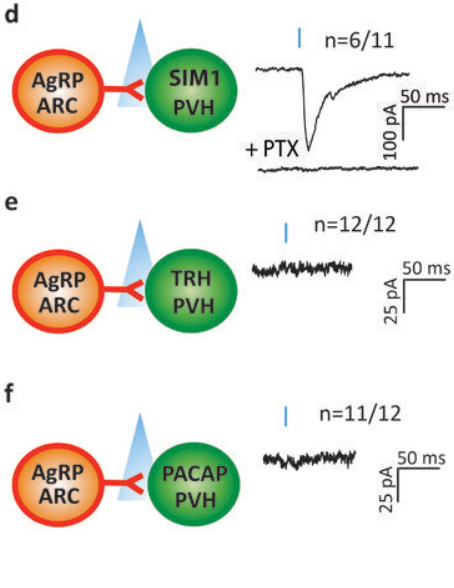

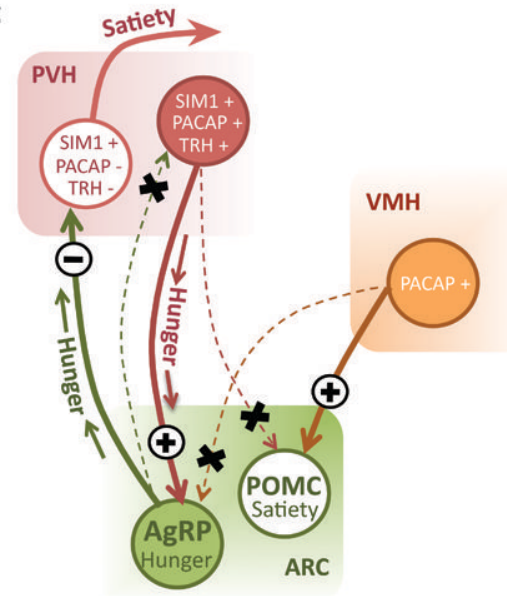

Figure 3. Fidelity of TRH ${ }^{\mathrm{PVH}} / \mathrm{PACAP} \mathrm{PVH}_{\rightarrow} \rightarrow \mathrm{ARC}$ and $\mathrm{AgRP} \mathrm{PRC}_{\rightarrow} \rightarrow \mathrm{PVH}$ circuitry

a-f, Left, schematic shows connections being tested. Right, representative traces showing assessment of light-evoked EPSCs (a-c) or IPSCs (d-f) with blue tic indicating the light pulse (473 nm wavelength, $2 \mathrm{msec}$ ). Mice used were (a) Trh-ires-Cre; Pomc-hrGFP, (b-c) Pacap-ires-Cre; Pomc-hrGFP, (d) Agrp-ires-Cre; Sim1-Cre; R26-loxSTOPlox-L10-GFP mice for visualization of SIM1 neurons, (e) Agrp-ires-Cre; Trh-ires-Cre injected with AAV8-DIO-mCherry into the PVH for visualization of TRH neurons and (f) Agrp-ires-Cre; Pacap-ires-Cre; R26-loxSTOPlox-L10-GFP mice for visualization of PACAP neurons. $\mathrm{CNQX}=\mathrm{AMPA}$ receptor blocker. $\mathrm{PTX}=\mathrm{GABA}_{\mathrm{A}}$ receptor blocker. $(\mathrm{g})$ Model summarizing reciprocal circuitry and its fidelity. 
a

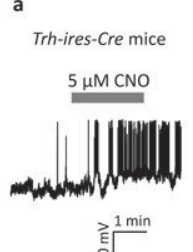

Pacap-ires-Cre mice

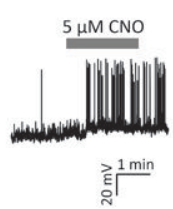

हो

g

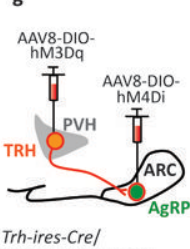

Trh-ires-Cre/

Agrp-ires-Cre mice

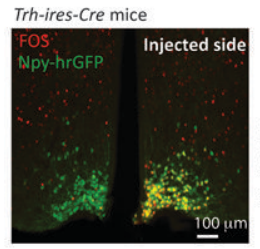

e
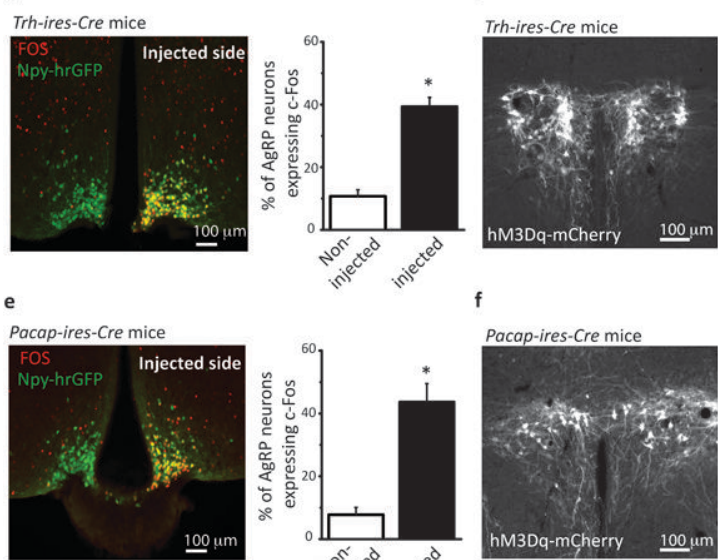

Trh-ires-Cre mice
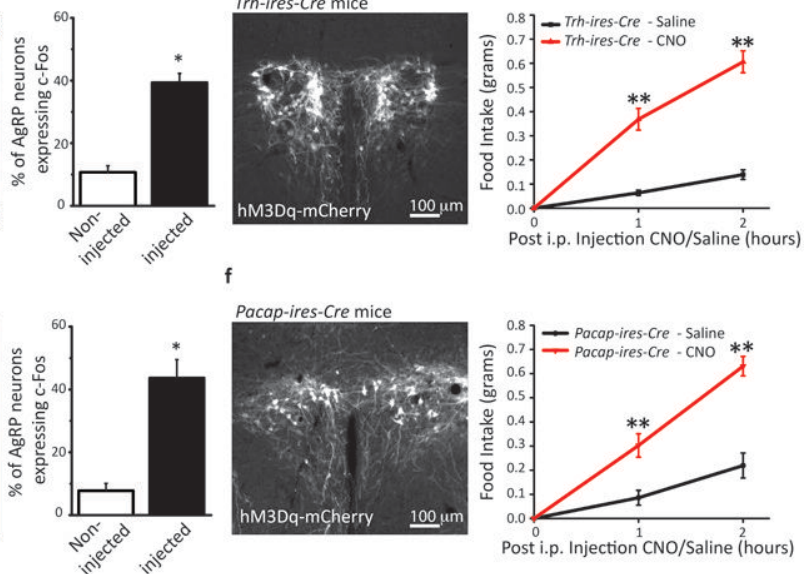

Pacap-ires-Cre mice


Post i.p. Injection CNO/Saline (hours)
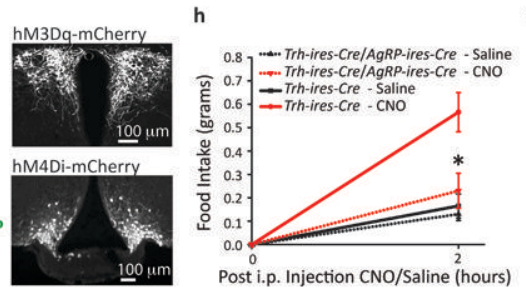

i j ,
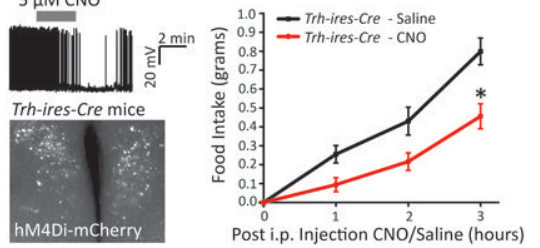

Figure 4. DREADD-mediated manipulation of TRHPVH or PACAPPVH neurons mediates feeding through AgRP neurons

a,d, Membrane potential and firing rate of $(\mathbf{a}) \mathrm{TRH}^{\mathrm{PVH}}$ or (d) $\mathrm{PACAP} \mathrm{PVH}^{\mathrm{PV}}$ neurons transduced with AAV8-DIO-hM3Dq-mCherry upon CNO application.

b,e, AAV8-DIO-hM3Dq-mCherry was transduced unilaterally into the PVH of (b) Trh-iresCre or (e) Pacap-ires-Cre mice and ipsilateral induction of Fos (red) was assessed in AgRP neurons (marked by hrGFP, green) $3 \mathrm{hrs}$ following $\mathrm{CNO}\left(0.3 \mathrm{mg} \mathrm{kg}^{-1}\right)$ injection $(\mathrm{n}=3, \mathrm{n}=3$; respectively).

c,f, Left, AAV8-DIO-hM3Dq-mCherry (white) was transduced bilaterally into the PVH of (c) Trh-ires-Cre or (f) Pacap-ires-Cre mice. Right, light-cycle food intake after injection of saline (black) or $\mathrm{CNO}$ (red; $\left.0.3 \mathrm{mg} \mathrm{kg}^{-1}\right)(\mathrm{n}=7-8$ animals per condition; experiment replicated three times per animal).

g,h, Simultaneous inhibition of AgRPARC neurons with activation of TRH ${ }^{\mathrm{PVH}}$ neurons attenuates food intake. (g) Sagittal schematic of occlusion study, whereby AAV8-DIOhM3Dq-mCherry (white) was transduced bilaterally into the PVH (Top) and AAV8-DIOhM4Di-mCherry (white) was transduced bilaterally into the ARC (Bottom) of Trh-ires-Cre; Agrp-ires-Cre mice. (h) light-cycle food intake after injection of saline (black) or $\mathrm{CNO}$ (red; $0.3 \mathrm{mg} \mathrm{kg}^{-1}$ ) in Trh-ires-Cre; Agrp-ires-Cre (dotted; hM3Dq in PVH and hM4Di in ARC) and Trh-ires-Cre (solid; hM3Dq in PVH) mice ( $\mathrm{n}=4$ animals per condition; experiment replicated three times per animal).

i, (Top) Membrane potential and firing rate of TRH ${ }^{\mathrm{PVH}}$ neurons transduced with AAV8DIO-hM4Di-mCherry upon CNO application. (Bottom) AAV8-DIO-hM4Di-mCherry (white) was transduced bilaterally into the PVH of Trh-ires-Cre mice.

j, Dark-cycle food intake after injection of saline (black) or CNO (red; $\left.0.3 \mathrm{mg} \mathrm{kg}^{-1}\right)(\mathrm{n}=4$ animals per condition; experiment replicated three times per animal). Results are shown as mean \pm SEM, $*=p<0.05, * *=p<0.001$; see Supplementary Information for statistical analyses.

b,e. $\mathrm{n}=3$ for each group. Data represent mean \pm SEM. $\mathrm{P}$ values for unpaired comparisons were calculated by two-tailed Student's t-test. ${ }^{*} \mathrm{p}<0.05$. 
c, $\mathbf{f}$. $\mathrm{n}=8$ for Trh-ires-Cre group; $\mathrm{n}=7$ for Pacap-ires-Cre group. Data represent mean \pm SEM. Two-way repeated measures ANOVA detected significant interaction of 'time' and 'treatment'. $\mathrm{F}_{3,20}=56.13$, **p $<0.001 ; \mathrm{F}_{3,18}=0.056, * * \mathrm{p}<0.001$; respectively. Sidak's post-hoc test shows significant difference between 'time' and 'treatment' at 1 and 2 hrs as indicated; respectively.

h. $\mathrm{n}=4$ for each group. Data represent mean \pm SEM. Two-way repeated measures ANOVA detected significant interaction of 'genotype' and 'treatment'. $\mathrm{F}_{3,18}=6.083,{ }^{*} \mathrm{p}<0.05$.

Sidak's post-hoc test shows significant difference between 'genotype' and 'treatment' as indicated.

j. $\mathrm{n}=4$. Data represent mean \pm SEM. Two-way repeated measures ANOVA detected significant interaction of 'time' and 'treatment'. $F_{3,18}=3.962$, * $\mathrm{p}<0.05$. Sidak's post-hoc test shows significant difference between 'time' and 'treatment' at $3 \mathrm{hrs}$ as indicated. 